an abundance of nitrogen, phosphorus and potassium contained no sulfates.

8. Where no sulfates were added to the soil, $90 \%$ or more of the total sulfur was found in the form of unoxidized sulfur, probably in proteins. In the normally grown plants examined this was from $50-65 \%$ of the total. The plant was evidently very economical of its supply and made healthy, vigorous growth where no sulfates could be found in the tissue.

To Prof. E. B. Hart, at whose suggestion this work was undertaken, the author wishes to express thanks for his interest and encouragement.

BIBLIOGRAPHY.

(I) J. Biol Chem., 9, 439-462 (I911).

(2) J. Chem. Soc., 99, 2336 (I9II).

(3) J. Biol. Chem., 13, 463 (1913).

(4) Crells. Anal., 2, 38, 68, I36 1790 (1 799).

(5) Berzelius, Jahrb., 6, 242; 12, 263.

(6) Ann. chim. phys., II, 44, 214 (I830); II, 53, I8I (I833).

(7) J. prakt. Chem., 19, 218; Pogg. Ann., 49, 340.

(8) Ann., 125, 257.

(9) Ber., 30, 2332 (1897); Chem. Zentr., II, 922; Arch. Pharm., 235, 44.

(Io) J. Pharm., 27, 39; Ann., 34, 223.

(II) Van Rijn, "Die Glykoside," pp. 183-198.

(12) Arch. Pharm., 240, 16I (1902).

(13) Pharm. Post., 27, 33.

(14) Chem. Zentr., 75, I, I46I (rg04).

(I5) Ibid., 8I, I, 375 (1910).

(16) Z. anal. Chem., 30, 66I; Landwirt. Vers. Sta., 4I, 176.

(17) Arch. Pharm., 240, 161.

(18) 26th Ann. Rept., 1903, N. Car., p. 70.

(19) This Journal, 35, 1628 (1913).

(20) Ibid., 33, 549 (I911); Wis. Expt. Sta. Research, Bull. I4.

(21) Ky. Agr. Exp. Sta., Bull. 174 (1913).

(22) Mazières, Le Engrais, June 23, 19r1; Boulanger, Compt. Rend. Hebdom., Feb. 5, 1912, July 22, 1912; Demolon, Compt. Rend. Hebdom., Feb. 19, 1912; Chaucrin and Desriot, Journ. D'Agric. Prat., Mar. 12, 1912; Vercier, Prog. Agric. et Vit., Nov. I, 1912.

(23) Biochem. Z., 29, 429-438.

(24) Am. J. Physiol., 6, 450 (1902).

[From thE LABORATORY OF BIOLOGICAI ChEMistry, WASHINGTON UNIVERSITY, ST. Louis, Mo.]

\title{
A METHOD FOR THE DETERMINATION OF FAT IN MILK (NEPHELOMETRIC METHOD).
} BY W. R. BLOoR.

Received April 16; 1914

The methods for the determination of fat in milk, in common use at the present time, may be roughly classified as follows:

(I) Rapid methods, like the Babcock and Gerber methods, which de- 
pend on the separation of the fat by centrifugation after treatment of the milk with reagents which alter the protein constituents. The separated fat is collected into a narrow portion of the vessel and the amount of fat determined by the length of the fat column.

(2) Methods like the Rose-Gottlieb-Farnsteiner and Meigs methods which depend on the direct extraction of the fat from the milk with fat solvents and determination by weighing the extracted material.

(3) Methods like the Adams' which depend on the extraction and weighing of fat from the milk after drying on fat-free filter paper or sand.

The method to be described is based on a new principle--the determination of the fat by comparison of the light reflecting power of a watery suspension of the milk fat with that of a similar suspension of a standard fat (triolein), making use of the nephelometer. The watery suspension is obtained by flocking a colloidal solution of the fat with an electrolyte (hydrochloric acid has been found most suitable). The colloidal solution is produced by mixing an alcoholic solution of the fat with distilled water. The same principle has been made the basis of a method for the determination of fat in blood. ${ }^{1}$

The nephelometric method possesses the advantage that it requires only a very small amount of milk-ordinarily $\mathrm{I}$ cc.- - and should therefore be of special value in working with human milk or with that of small animals where it is inconvenient or impossible to obtain enough for the ordinary determinations. The time, required is not greater than that needed for the "rapid" methods, while the accuracy is limited only by the accuracy of the instruments. The nephelometer is simple both in principle and construction and, while but little known at present, promises to come into general use, since it appears to be applicable to most quantitative uses, especially in the accurate determination of small amounts of material.

The procedure is as follows: One cubic centimeter of the milk, measured with an accurate pipette, is run slowly and with stirring into about $8 \mathrm{occ}$. of an alcohol-ether mixture (containing 3 parts of redistilled alcohol and I part of redistilled ether), in a roo cc. graduated flask. (The measurement may be checked by determining the weight of the added milk.) The mixture is raised to boiling by immersion in a boiling water bath, cooled to room temperature, made up to Ioo cc. with the alcohol-ether, shaken and filtered. The filtrate is clear and almost colorless.

For the determination, $5 \mathrm{cc}$. of the solution are run from a pipette, slowly with stirring, into Ioo cc. of distilled water in a beaker, producing a slightly opalescent colloidal solution. The point of the pipette must be kept below the surface of the liquid during the outflow. A similar solution is prepared with $5 \mathrm{cc}$. of the standard fat solution (see below). To the

${ }^{1}$ Bloor, J. Biol. Chem., 17, 377 (1914). 
standard and to the test solutions are added, simultaneously, ro cc. portions of dilute (10\%) hydrochloric acid and, after stirring, the solutions. allowed to stand for five minutes, after which they are transferred to the comparison tubes of the nephelometer.

For the comparison, the two tubes, filled to the same height with the solutions, are placed in the nephelometer with the standard tube always. on the same side. If bubbles appear in the walls of the tubes they are removed by inverting two or three times. The movable jacket on the standard side is set at a convenient point, generally $50 \mathrm{~mm}$. (Richards" nephelometer), and comparisons made by adjusting the jacket on the test solution until the images of the two tubes show equal illumination. At least five readings are taken, alternately from above and below, and the average taken as the reading. This reading is corrected from the calibration curve of the instrument and the fat value of the milk calculated from the corrected reading.

The standard solution used is an alcohol-ether solution of pure triolein, made with freshly distilled absolute alcohol and pure dry ether, of which $5 \mathrm{cc}$. contains about $2 \mathrm{mg}$. of fat.

Remarks on the Procedure.-The application of the nephelometric principle and the use of the Richards' nephelometer in the determination of fats have been discussed in a previous paper ${ }^{1}$ and only the points essential to the use with milk will be mentioned here.

The Extraction.-The solvent combines the penetrating power of alcohol with the greater solvent power of ether. Running the milk slowly into the solvent which is kept in motion, causes the precipitation of the proteins in a finely divided flocculent form-in excellent condition for extraction. Under these conditions the presence of the great excess of: solvent and the short heating is adequate for complete extraction.

The Standard.-The choice of triolein is empirical, triolein being readily obtainable of a good degree of purity.

Choice of Time for Comparison.-Both the triolein and the milk fat solutions change (decrease) slowly in value after the addition of the precipitant. The rate of change is, however, practically the same in both for a period of an hour or more, so that if the precipitating acid is added to both simultaneously, the readings may be made at once. Ordinarily, however, about five minutes is given to allow for slight differences in the time of addition of the acid.

The Nephelometer-Calibration.-A form ${ }^{2}$ of the Richards' nephelometer $^{3}$ was used. It was found that the addition of a rack and pinion to the jacket on the comparison side was a great convenience. Matched.

${ }^{1}$ Bloor, Loc. cit.

2 Made by the International Instrument Company, of Cambridge Mass.

${ }^{3}$ T. W. Richards, $Z$. anorg, Chem., 8, 269 (I895); Richards and Wells, Am. Chem. $J ., 3$ I, 235, (I904). 
test tubes are used for comparison tubes and as it was not possible to find two tubes which, when filled with the same solution, would give the same readings on both sides of the instrument, the tubes were marked and always used on the same side, the one used for the standard solution being on the left. The average of many readings of the right hand tube was then taken as the potential height of the standard.

Lacking a nephelometer, many colorimeters may be adapted for the purpose, as has been shown by Kober ${ }^{1}$ with the Duboscq colorimeter, and the author with the Schreiner ${ }^{2}$ instrument.

Since the amount of light reflected is not exactly proportional to the depth and fat value of the solutions (because of different distances of the reflecting surfaces from the eye, absorption of light by the upper layers of liquid, different rates of flocking in solutions of different concentration, etc.), it is necessary to calibrate the nephelometer for different strengths of test solution, and for different standards, if more than one is used. The values obtained are plotted on a curve and corrections in the readings made from it.

Again, since the total light reflected from a given depth of solution depends as well on the size of the suspended particles as on their number, it is obvious that success with a nephelometric method depends on keeping as constant as possible those physical and chemical conditions which influence the aggregation of the particles. The concentration of alcoholether and acid, the rate of addition of the alcoholic fat solution, etc., should be the same; also the solutions to be compared should not be too far different in value, since strong colloidal solutions flock more quickly than weak ones. (Readings above $70 \mathrm{~mm}$. and below $30 \mathrm{~mm}$. with the standard at $50 \mathrm{~mm}$. are rejected.)

The calibration of the nephelometer for a given standard is carried out as follows: Suspensions of triolein of various known values are prepared as in the method, and compared with the similarly prepared standard triolein suspension in the nephelometer, with the movable jacket on the standard set as its usual place. The readings obtained are compared with the theoretical readings for the different values and the correction for each strength of solution determined. From these values a curve is plotted, from which intermediate values are obtained. In general, it is found that suspensions stronger than the standard give readings higher (i. e., lower fat values) than the theoretical, and solutions weaker than the standard give lower readings, indicating that probably the greater speed of flocking in the stronger solutions is the main factor in the abnormal readings.

Correction for Reagents. - When freshly distilled alcohol and ether are used it is not ordinarily necessary to make any correction for reagents.

${ }^{1}$ Kober, J. Biol. Chem., 13, 485 (19r3).

2 Bloor, Proc. Am. Chem. Soc., Rochester, I9r3. 
Results.-Duplicate determinations made on the same milk agree with one another within the limits of error of the instrument (about $3 \%$ ).

In the table below comparison is made of values obtained by the nephelometric method, the Babcock method and also in some cases, the Adams' method. In using the Babcock method, a calibrated pipette and specially prepared bottles were used. The cows' milk was mixed dairy milk collected from various sources. The human milk was from patients in the obstetric division of the Washington University Hospital, for which I am indebted to the kindness of Professor Henry Schwarz and Doctor Q. U. Newell. The samples were from cases in various early stages of lactation and were selected so as to obtain as wide range of fat values as possible.

Table I.-Comparison of Results Obtained by the Nephelometric and other METHODS FOR FAT IN MILK.

\begin{tabular}{|c|c|c|c|}
\hline \\
\hline Milk sample. & Babcock. & Nephelometric. & (Soxhlet). \\
\hline$\ldots \ldots \ldots \ldots \ldots \ldots \ldots$ & 2.9 & 2.85 & . \\
\hline B. Kingston, Can $\ldots \ldots \ldots \ldots \ldots \ldots \ldots \ldots$ & $3 \cdot 1$ & 3.00 & . \\
\hline Hospital supply I., St. Louis, Mo............ & $3 \cdot 5$ & 3.6 & . \\
\hline U. D. I., St. Louis, Mo.................... & 3.0 & $3 . I$ & $3.0 \mathbf{r}$ \\
\hline Hospital supply II, St. Louis, Mo............ & 3.0 & 3.1 & $\cdots$ \\
\hline M. Kirkwood, Mo $\ldots \ldots \ldots \ldots \ldots \ldots \ldots$ & 3.6 & 3.8 & 3.80 \\
\hline 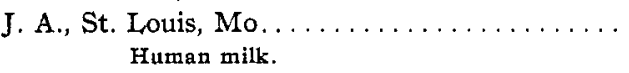 & $3 \cdot 5$ & 3.6 & 3.77 \\
\hline I. L. 22 days post partum.............. & $4 \cdot 7$ & 4.8 & $4 \cdot 70$ \\
\hline II. V. Io days pp. (child still-born) $\ldots \ldots \ldots \ldots$ & 8.2 & 8.1 & . \\
\hline III. $W$. I I days $p p \ldots \ldots \ldots \ldots \ldots \ldots \ldots$ & $3 \cdot 9$ & 3.83 & . \\
\hline 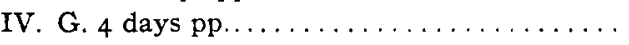 & $3 \cdot 75$ & 3.8 & . \\
\hline V. N. 3 days pp. (colostrum) ............. & $3 \cdot 3$ & 3.4 & . \\
\hline 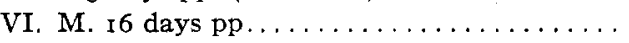 & 2,0 & 2.2 & 2. I 5 \\
\hline VII. B. 8 days pp. (breast caked a little) ... . . & 5.6 & 5.60 & $5 \cdot 7 \mathrm{I}$ \\
\hline
\end{tabular}

The preliminary work on this method was done in the Gordon Hall Laboratories of Chemistry of Queens' University and in the Kingston Dairy School at Kingston, Canada, and I wish in conclusion to express my appreciation of the kindness of Professor W. L. Goodwin, of the University, and of Mr. Zufeldt, Director of the Dairy School, in placing at my disposal the facilities of these institutions.

[Contribution from the Harriman Research Laboratory, RoOsevelt Hospital, NEW YORK.]

\section{NEPHELOMETRY IN THE STUDY OF NUCLEASES. ${ }^{1}$}

By Philip Adolph Kober and Sara S. Graves.

Received April 8, 1914.

TABLE OF CONTENTS.

I. Introduction. II. Method: A. Precipitant for Yeast Nucleic Acids; B. Experimental Work: (I) Preparation of Egg Albumin; (2) Use of Egg Albumin;

${ }^{1}$ Read at the Cincinnati Meeting, Am. Chem. Soc., April, I9r 4. 